\title{
Cell-penetrating peptides: Possible transduction mechanisms and therapeutic applications (Review)
}

\author{
ZHENGRONG GUO $^{1,2}$, HUANYAN PENG $^{1,3}$, JIWEN KANG $^{1}$ and DIANXING SUN ${ }^{1}$ \\ ${ }^{1}$ The Liver Diseases Diagnosis and Treatment Center of PLA, Bethune International Peace Hospital, Shijiazhuang, \\ Hebei 050082; ${ }^{2}$ Department of Gastroenterology, The First Hospital of Shijiazhuang City, Shijiazhuang, \\ Hebei 050011; ${ }^{3}$ Hebei Medical University Graduate School, Shijiazhuang, Hebei 050017, P.R. China
}

Received December 23, 2015; Accepted March 9, 2016

DOI: $10.3892 /$ br.2016.639

\begin{abstract}
Cell-penetrating peptides (CPPs), also known as protein transduction domains, are a class of diverse peptides with 5-30 amino acids. CPPs are divided into cationic, amphipathic and hydrophobic CPPs. They are able to carry small molecules, plasmid DNA, small interfering RNA, proteins, viruses, imaging agents and other various nanoparticles across the cellular membrane, resulting in internalization of the intact cargos. However, the mechanisms of CPP internalization remain to be elucidated. Recently, CPPs have received considerable attention due to their high transduction efficiency and low cytotoxicity. These peptides have a significant potential for diagnostic and therapeutic applications, such as delivery of fluorescent or radioactive compounds for imaging, delivery of peptides and proteins for therapeutic application, and delivery of molecules into induced pluripotent stem cells for directing differentiation. The present study reviews the classifications and transduction mechanisms of CPPs, as well as their potential applications.
\end{abstract}

\section{Contents}

1. Introduction

2. Classification of cell-penetrating peptides

3. Uptake mechanism of cell-penetrating peptides

4. Application of cell-penetrating peptides

5. Conclusion

Correspondence to: Professor Dianxing Sun, The Liver Diseases Diagnosis and Treatment Center of PLA, Bethune International Peace Hospital, 398 West Zhongshan Road, Shijiazhuang, Hebei 050082, P.R. China

E-mail: sundianxing@hotmail.com

Key words: cell-penetrating peptides, protein transduction domain, peptide therapeutic, internalization

\section{Introduction}

The cellular membrane is an effective semi-permeable barrier that is essential for cell survival and function. However, it is also a major obstacle for intracellular delivery of cargos for diagnosis and treatment of human diseases. Small molecules enter cells through specific carriers and channels in the membrane. However, macromolecules are generally unable to use these modes of entry into cells. Thus, it is important to develop tools to facilitate cellular uptake of large molecules for basic research and biomedical applications.

Cell-penetrating peptides (CPPs) are a promising class of short peptides with the ability to translocate across the cell membrane (1). CPPs generally contain 5-30 amino acids. In 1988, two independent groups reported transactivator of transcription (Tat) protein of the human immunodeficiency virus (HIV) as the first CPP. Tat has the ability to enter cultured mammalian cells and promote viral gene expression $(2,3)$. Subsequently, several polycationic CPPs have been identified. For example, Antp, the third helix of the homeotic protein of Drosophila melanogaster Antennapedia, can enter nerve cells and regulate neural morphogenesis (4), and vp22, the herpes virus structural protein, has potential in protein delivery (5). CPPs can act as carriers as they have the ability to deliver macromolecular cargos, such as polypeptides (6), nanoparticles (7) and oligonucleotides (8) into cells. However, the mechanisms of CPP internalization are mostly unknown. The possible mechanisms are direct penetration, endocytosis and translocation through the formation of a transitory structure. The present review provides a broad overview of the classification, mechanisms of transduction and potential applications of CPPs.

\section{Classification of cell-penetrating peptides}

General. The classification of CPPs varies based on their physicochemical properties. In general, CPPs can be divided into three classes: Cationic, amphipathic and hydrophobic (Table I) (9). Currently, >100 different CPPs have been reported and patented. More than $83 \%$ of CPPs, which includes Tat, the first identified CPP, have a net-positive charge. Amphipathic CPPs, which comprise cationic and anionic peptides, are $44 \%$ of CPPS, while only $15 \%$ of CPPs are hydrophobic (10). 
Cationic CPPs. Cationic peptides are a class of peptides that contain a high positive charge. The first CPP derived from the HIV-1 protein Tat is a cationic peptide. The majority of cationic peptides are naturally occurring peptide sequences. Recently, several artificial cationic peptides have been developed, includeing homo-polymers of arginine (11) and lysine (12). Studies on arginine-based peptides (from R3 to R12) have shown that the minimal sequence necessary for cellular uptake is six arginines, and that increasing the number of arginine residues increased transduction efficiency (13). In comparison, increasing the number of lysine residues reduced uptake of polylysine CPPs. However, arginine and lysine homopolymers $>12$ amino acids show reduced transduction efficiency (14). Nuclear localization sequences (NLSs) are a special type of cationic CPPs, which facilitate translocation into the nucleus through the nuclear pore complex (15).

Amphipathic CPPs. Amphipathic CPPs are chimeric peptides, several of which are obtained by the covalent attachment of a hydrophobic domain to an NLS, such as MAP and MPG sequences (16). For example, MPG (GALFLGWLGAAGSTMGAPKKKRKV) is based on the SV40 NLS PKKRKV, and the hydrophobic domain derived from the fusion sequence of the HIV glycoprotein 41 (17). Several other primary amphipathic CPPs, such as pVEC (18), ARF (1-22) (19), and BPrPp (1-28) (20), are derived from natural proteins.

Amphipathic $\alpha$-helix is the most common structural motif of numerous peptides and proteins. Amphipathic $\alpha$-helical CPPs have a highly hydrophobic patch on one face, whereas the other face can be cationic, anionic or polar. An amphipathic $\beta$-sheet peptide is developed based on one hydrophobic and one hydrophilic stretch of amino acids exposed to the solvent. Studies on VT5 (DPKGDPKGVTVTVTVTVTGKGDPKPD) have shown that the formation of $\beta$-sheets is essential for its cellular uptake $(21,22)$. Proline-rich CPPs are a family of CPPs with diverse sequences and structures. However, their common structure has a proline pyrrolidine template (23).

Hydrophobic CPPs. Hydrophobic CPPs are derived from signal peptide sequences and contain only apolar residues. These peptides include transportan (24), stapled peptides (25), prenylated peptides (26) and pepducins (27). Thus far, only a few hydrophobic CPPs, including SG3 (28), Pep-7 (29), and fibroblast-growth factor (30), have been reported. Compared to cationic and amphipathic peptides, the potential application and mechanism of hydrophobic CPP translocation are less studied.

\section{Uptake mechanism of cell-penetrating peptides}

The intracellular CPP uptake mechanism has remained elusive since the discovery that Tat was cell permeable. Although the exact mechanism of entrance of CPPs into cells has not been completely resolved (31-33), it is widely believed that the CPP uptake mechanism varies for different CPP families, and the majority of CPPs have two or more pathways depending on the experimental conditions. Recent advances have shown that that there are three mechanisms for CPP translocation across the cellular membrane (Table II) $(34,35)$.
Direct penetration. The direct penetration pathway is energy-independent. Early studies showed that Tat and pAntp can enter a cell at $4^{\circ} \mathrm{C}(36,37)$. Veach et al $(38)$ reported that Tat has the same cell-penetrating efficiency at 4 and $37^{\circ} \mathrm{C}$, and the internalization process is not blocked in cells without adenosine triphosphate. In order to prove this mechanism, certain membrane models have been constructed, such as transient pore formation (39), the carpet-like model (40) and the membrane-thinning model (41). The common features of these models are that CPPs first bind to the cell membrane via electrostatic or hydrophobic interactions and induce a brief or prolonged membrane destabilization of the binding sites, leading to CPP entrance into the cells. The internalization coefficient is relative to the peptide concentration, peptide sequence and lipid composition in each model.

Endocytosis-mediated translocation. Unlike direct penetration, this pathway is energy-dependent. During the course of endocytosis-mediated translocation, cells obtain energy from outside of the membrane. Richard et al (42) studied the mechanisms of Tat and polyarginine translocation using fluorescence microscopy in living cells. They found that Tat and polyarginine enter into the cells via endocytosis. This transduction mechanism is further divided into two classes of endoycytosis: Phagocytosis and pinocytosis. Phagocytosis is used for absorption of large particles and pinocytosis is used for solute absorption (32). Pinocytosis exists in all cell types. Endocytosis of CPP as macropinocytosis, clathrin-dependent pathway, cholesterol-dependent clathrin-mediated pathway and caveolin/clathrin-independent pathway has been reported (43-45).

Translocation via the formation of a transitory membrane structure. The translocation via the formation of a transitory membrane structure mechanism depends on the structure of inverted micelles to allow the peptide to bind a hydrophilic environment (46). In this model, a penetrating dimer combines with the negatively charged phospholipids leading to the formation of an inverted micelle inside the lipid bilayer (9). Arginine-rich peptides permeate the plasma membrane via this pathway (47).

Taken together, the CPP uptake mechanism remains largely unknown (43). The mechanism of CPP uptake may vary considerably according to CPP, CPP-cargo, cell types and concentration $(17,48,49)$. Additionally, physicochemical parameters, incubation temperature and time should also be considered (50,51). Endocytosis is believed to be the dominant mechanism for the majority of CPP uptake. However, it is most likely that different transduction mechanisms may contribute under different conditions for the majority, if not all, CPPs.

\section{Application of cell-penetrating peptides}

CPPs have the capability to deliver various cargoes without causing any cellular injury. Thus, a wide range of CPP applications are being developed, such as imaging agents and vehicles to deliver therapeutic drugs, small interfering RNA (siRNA), nucleotides, proteins and peptides. The main applications of CPPs are shown in Table III. 
Table I. Cell-penetrating peptide classifications and sequences.

\begin{tabular}{|c|c|c|c|c|c|}
\hline Study, year & Classification & Peptide & Sequences & Main trait & Refs. \\
\hline $\begin{array}{l}\text { Green and Loewenstein, } 1988 \\
\text { Frankel and Pabo, } 1988\end{array}$ & Cationic & Tat & GRKKRRQRRRPPQ & High positive charge & $\begin{array}{l}(2) \\
(3)\end{array}$ \\
\hline Joliot et al, 1991 & & Antp & RQIKIWFQNRRMKWKK & & (4) \\
\hline Ragin et al, 2002 & & NLS & CGYGPKKKRKVGG & & (15) \\
\hline Wender et al, 2000 & & 8-Arginine & RRRRRRRR & & (11) \\
\hline Mai et al, 2002 & & 8-Lysine & KKKKKKKK & & (12) \\
\hline Oehlke et al, 1998 & Amphipathic & MPG & $\begin{array}{l}\text { GLAFLGFLGAAGSTM } \\
\text { GAWSQPKKKRKV }\end{array}$ & Chimeric peptides & (16) \\
\hline Deshayes et al, 2004 & & pVEC & LLIILRRRIRKQAHAHSK & & (17) \\
\hline Nan et al, 2011 & & ARF (1-22) & $\begin{array}{l}\text { MVRRFLVTL } \\
\text { RIRRACGPPRVRV }\end{array}$ & & (18) \\
\hline Johansson et al, 2008 & & $\mathrm{BPrPp}(1-28)$ & $\begin{array}{l}\text { MVKSKIGSWILVLFV } \\
\text { SDVGLCKKRP }\end{array}$ & & (19) \\
\hline Elliot and O'Hare, 1997 & & VP22 & $\begin{array}{l}\text { NAATATRGRSAASRPTQR } \\
\text { PRAPARSASRPRRPVQ }\end{array}$ & & (5) \\
\hline Magzoub et al, 2006 & & VT5 & $\begin{array}{l}\text { DPKGDPKGVTVT } \\
\text { VTVTVTGKGDPKPD }\end{array}$ & & (20) \\
\hline Eguchi and Dowdy, 2009 & & & & & (21) \\
\hline Oehlke et al, 1998 & & MAP & $\begin{array}{l}\text { KLALKLALK } \\
\text { ALKAALKLA }\end{array}$ & & (16) \\
\hline Pujals and Giralt, 2008 & Hydrophobic & Transportan & $\begin{array}{l}\text { GWTLNSAGYLLG } \\
\text { KINLKALAALAKKIL }\end{array}$ & $\begin{array}{l}\text { Contain only apolar residues; } \\
\text { have a low net charge }\end{array}$ & (23) \\
\hline Gao et al, 2011 & & SG3 & RLSGMNEVLSFRW & & (28) \\
\hline Gao et al, 2002 & & Pep-7 & SDLWEMMMVSLACQY & & (29) \\
\hline Nakayama et al, 2011 & & FGF & PIEVCMYREP & & (30) \\
\hline
\end{tabular}

Table II. Cell-penetrating peptide uptake mechanisms.

\begin{tabular}{llll}
\hline Study, year & \multicolumn{1}{c}{ Pathway } & \multicolumn{1}{c}{ Main trait } & Examples \\
\hline Vives et al, 1997 & Direct penetration & Energy-independent & Tat peptide \\
Derossi et al, 1994 & Direct penetration & Energy-independent & pAntp \\
Richard et al, 2003 & Endocytosis & Energy-dependent & Polyarginine \\
Nan et al, 2011 & Endocytosis & Energy-dependent & ARF (1-22) \\
Kawamoto et al, 2011 & Via the formation of a & Formation of the & Arginine-rich \\
& transitory membrane structure & inverted micelles & peptide \\
\hline
\end{tabular}

Imaging. Intracellular imaging has potential to improve disease management by detecting disease markers, but its application is limited due to the poor permeability of proteins. CPPs can function as vectors to carry fluorescent particles into cells due to their internalization properties and have become promising tools for delivering imaging agents, contrast agents and quantum dots (QDs) in the field of imaging. The advantage of such imaging technology is the ability to visualize and quantify biomarkers or biochemical and cellular processes, detect the stage of diseases, identify the extent of disease and measure the effect of treatment $(52,53)$.

The size of QDs generally falls within the 2-10 nanometer range; QDs are brighter and more stable against photobleaching than standard fluorescent indicators, and thus QDs have emerged as an alternative to organic dyes and fluorescent proteins (54). QDs have been extensively studied for biological imaging, but their inability to cross the cellular membrane has limited their application. This limitation has been overcome by the discovery of CPPs. Ruan et al (55) used Tat peptide-conjugated QDs (Tat-QDs) to examine the complex behavior of nanoparticle probes in live cells and found that Tat-QDs are internalized by macropinocytosis. The internalized Tat-QDs are tethered to the inner vesicle surfaces and are trapped in cytoplasmic organelles. The study also revealed that Tat-QDs strongly bind to cellular membrane structures. Their research provides new insights for molecular 
Table III. Cell-penetrating peptide applications.

\begin{tabular}{|c|c|c|c|}
\hline Study, year & Application & Examples & Refs. \\
\hline Ruan et al, 2007 & \multirow[t]{4}{*}{ Imaging } & Tat-QDs & $(55)$ \\
\hline Lei et al, 2008 & & & $(56)$ \\
\hline Prantner et al, 2003 & & Gd-DOTA-D-Tat & $(57)$ \\
\hline Polyakov et al, 2000 & & Tat- $(99 \mathrm{~m}) \mathrm{Tc}$ & $(58)$ \\
\hline Deshayes et al, 2010 & \multirow[t]{5}{*}{ Anti-inflammation } & CPP-PNA & $(63)$ \\
\hline Tan et al, 2005 & & & $(64)$ \\
\hline Tilley et al, 2007 & & CPP-PMO & $(65)$ \\
\hline Davé et al, 2007 & & CPP-NBD & $(71)$ \\
\hline Peterson et al, 2011 & & Antp-NBD & $(72)$ \\
\hline Koshkaryev et al, 2013 & \multirow[t]{5}{*}{ Tumor therapy } & R8-DOPE-BLM & $(76)$ \\
\hline Walker et al, 2012 & & DOXO-ELP-CPP & $(77)$ \\
\hline Aroui et al, 2010 & & Dox & $(78)$ \\
\hline Dubikovskaya et al, 2008 & & Taxol & $(79)$ \\
\hline Lindgren et al, 2006 & & Methotrexate & $(80)$ \\
\hline Eguchi and Dowdy, 2009 & \multirow[t]{3}{*}{ Nucleic acid and Protein delivery } & CPP-siRNA & $(21)$ \\
\hline Muratovska and Eccles, 2004 & & & $(82)$ \\
\hline Favaro et al, 2014 & & T-Rp3 & (83) \\
\hline Eto et al, 2009 & Viral delivery & CPP-Adv & (86) \\
\hline
\end{tabular}

imaging and targeted therapy. In another study, Tat-QDs were efficiently introduced into living mesenchymal stem cells (56). Other imaging applications of CPPs have also been developed. The Gd-DOTA-D-Tat peptide conjugate can enter into the cell interior resulting in intracellular T1 relaxation enhancement (57); Tat-(99m)Tc conjugates can be applied for imaging and radiotherapy (58). Tat- $(99 \mathrm{~m}) \mathrm{Tc}$ conjugates have also been developed for imaging in prostate and breast cancer $(59,60)$. A hydrogen peroxide-activated CPP was developed to observe in vivo lung inflammation, suggesting that CPPs have the potential for imaging and treating diseases related to oxidative stress (61).

Anti-inflammation therapy. Antisense peptide nucleic acids (PNAs) have been shown to specifically inhibit gene expression and growth of Escherichia coli, and are a promising anti-inflammatroy agent (62). Accordingly, PNA conjugated with CPPs (CPP-PNA) have been developed for efficient delivery of PNAs (63). For example, administration of the acpP-targeting PNA conjugated to CPP into Escherichia coli K-12-infected BALB/c mice reduced bacterial blood contents, prevented fatal infection and enhanced survival of the infected mice (64). Similar results were observed for the CPP-PMO conjugate targeted to the same acpP administered to mice infected with Escherichia coli (65). The results demonstrated an antibiotic effect of these CPP-PNA conjugates.

Nuclear factor $-\kappa \mathrm{B}(\mathrm{NF}-\kappa \mathrm{B})$ has an important role in the inflammation response. Inflammatory cytokines, such as tumor necrosis factor (TNF) and interleukin-1 (IL-1), can activate $\mathrm{NF}-\kappa \mathrm{B}$ and induce the inflammatory reaction. It has been well documented that certain inflammatory diseases, such as rheumatoid arthritis (66), atherosclerosis (67), Parkinson's disease (68) and inflammatory bowel disorders (IBD) (69), are associated with the activation of NF- $\kappa \mathrm{B}$. IBD in particular is characterized by sustained upregulation of inflammatory factors, such as TNF- $\alpha$, IL- 6 and IL-1, accompanied by increased activity of $\mathrm{NF}-\kappa \mathrm{B}$. It has been proposed that blocking the activation of NF- $\kappa \mathrm{B}$ can prevent certain chronic inflammation (70). The NEMO binding domain (NBD) of IKK can block $\mathrm{NF}-\kappa \mathrm{B}$ activation. In a mouse model of IBD, intraperitoneal injection of CPP-NBD resulted in downregulation of inflammatory factors and amelioration of the disease (71), suggesting that CPP-NBD may be used in the treatment of IBD. In another study, intraperitoneal injection of Antp-NBD fusion peptide in a Duchenne muscular dystrophy mouse model decreased $\mathrm{NF}-\kappa \mathrm{B}$ activation and muscle necrosis, and increased muscle regeneration (72).

Tumor therapy. Cancer is an important public health issue and has become the leading killer of human beings (73). Conventional chemotherapy has a low drug concentration at local tumor areas and can cause severe side effects due to lack of tumor cell specificity (74). New efficient and tumor targeting strategies should be developed to overcome this limitation. Conjugation of anticancer agents with CPPs has improved tumor therapy. CPP-delivered anticancer therapeutics can increase cellular membrane permeability of anticancer drugs to target tumor cells, expanding the broad application of CPPs in tumor therapy (75). Bleomycin (BLM) is an anticancer drug that has been used extensively, but its efficiency depends on its cytosolic accumulation. The artificial R8-DOPE-BLM conjugate can enter into the cytosol and cause a stronger induction of tumor cell death and DNA damage in vitro compared to BLM (76). Elastin-like polypeptide (ELP) can passively accumulate in solid tumors and aggregate in tumor tissue when exposed to hyperthermia. Injection of a conjugate 
of doxorubicin with ELP and CPP in a C57BL/6 mouse breast cancer model resulted in augmented internalization of doxorubicin and reduced tumor size more than two-fold compared to free doxorubicin (77). Similar results have been obtained by conjugation of CPP with doxirubicin (78), Taxol (79) and methotrexate (80). These data demonstrate that CPP-delivered anticancer agents can improve drug concentration at the tumor tissue and increase the treatment effect.

Nucleic acid and protein delivery. Larger macromolecules, such as nucleic acids and proteins, are unable to penetrate the plasma membrane and enter into cells. CPPs can facilitate cellular uptake of large molecules and have been developed as a delivery tool for nucleic acids and proteins. siRNA have been widely used for gene silencing and used to treat diseases such as cancer, infectious diseases and genetic disorders (81). CPPs can overcome the barrier of poor permeability and lead to the internalization of siRNA (21). A CPP-siRNA complex synthesized via a disulfide bond has been shown to efficiently reduce transient and stable expression of reporter transgenes in several mammalian cell types (82), suggesting that CPP-siRNA has a potential application in siRNA-based therapy.

Recently, CPPs have also been conjugated to protein. A modular protein (T-Rp3) fused to an N-terminal DNA-binding domain and a C-terminal membrane Tat peptide was successfully expressed in Escherichia coli. Treatment of HeLa cells with this purified recombinant protein improved the delivery of T-Rp3 (83). Similarly, N-stearylated peptide has a low transfection activity; however, an N-terminal stearylated NLS (PKKKRKV) conjugated to CPP effectively promoted the nuclear translocation of $\mathrm{N}$-stearylated peptide (84).

Viral delivery. CPPs can also be applied to enhance the efficiency of viral transduction (85). Adenoviral vector (Adv) has been extensively used in basic and clinical research due to its high transduction efficiency. However, Adv has poor infection efficiency in cells lacking the primary adenovirus receptor, as well as the coxsackievirus receptor (86). Adv bound to CPP can overcome this barrier (87). Adv conjugated to CPPs (CPP-Adv) by chemical conjugation results in higher gene expression, indicating that CPP-modified Adv as a delivery vector is an attractive tool for transducing cells and gene therapy (86).

Directing induced pluripotent stem cells (iPS) differentiation. iPS generated directly from somatic cells can differentiate into various cell types (88). Delivering certain molecules into iPS cells can direct cell-type specific differentiation, which can be used for disease modeling, drug screening and cell transplantation therapies (89). However, these applications are limited as iPS cells are generally difficult to transfect. Previous studies have shown that transfecting certain cytokines and growth factors can promote human iPS cell differentiation into lung (90) and retinal cells (91), but these delivery tools are lentiviral or Advs. Viral vectors can infect iPS cells, but present a risk of genomic integration of exogenous viral genes (92). Plasmid DNA transfection with cationic lipids can overcome this risk; however, the transfection efficiency is relatively low (93). CPP may be a powerful tool for delivering exogenous proteins into iPS cells, eliminating the risk of exogenous genomic integration, while promoting high transduction efficiency.

\section{Conclusion}

CPPs are a class of small peptides 5-30 amino acids in length that have the potential to transport numerous types of therapeutic agents across the cellular membrane into cells. However, cellular CPP uptake mechanisms remain to be elucidated. CPPs have been widely used as a delivery vector due to their high transduction efficiency and capacity for delivering large molecules into a cell. CPPs are used to deliver fluorescent proteins to detect disease markers and manage disease. CPPs as vectors delivering therapeutic agents have proved effective in certain disease models, such as inflammatory disease and cancer. Additionally, CPPs can transport certain molecules into iPS cells to direct iPS cell-type specific differentiation. In conclusion, the application of CPPs for delivering a variety of agents into cells has promising clinical potential.

However, although there is a potential for CPP applications as diagnostic or therapeutic agents, there are no published human studies supporting their use. Several limitations should be addressed prior to using CPP-based diagnostic and therapeutics applications in the clinic. First, the best route of drug administration is oral uptake; however, there have been no detailed studies on the oral bioavailability of CPPs. Second, the majority of the reported CPPs are not tissue and organ-specific, which may cause severe side effects. Screening specific CPPs via a phage-display library may solve this problem. Additionally, kidney and liver toxicity should be considered as a new drug or therapeutic application.

\section{Acknowledgements}

The present study was supported by the National Natural Science Foundation of China (grant no. 81201297) and Chinese PLA project (grant no. 13QNP012).

\section{References}

1. Lindgren M, Hallbrink M, Prochiantz A and Langel U: Cell-penetrating peptides. Trends Pharmacol Sci 21: 99-103, 2000.

2. Green M and Loewenstein PM: Autonomous functional domains of chemically synthesized human immunodeficiency virus tat trans-activator protein. Cell 55: 1179-1188, 1988.

3. Frankel AD and Pabo CO: Cellular uptake of the tat protein from human immunodeficiency virus. Cell 55: 1189-1193, 1988.

4. Joliot A, Pernelle C, Deagostini-Bazin H and Prochiantz A: Antennapedia homeobox peptide regulates neural morphogenesis. Proc Natl Acad Sci USA 88: 1864-1868, 1991.

5. Elliott $\mathrm{G}$ and $\mathrm{O}^{\prime}$ Hare P: Intercellular trafficking and protein delivery by a herpesvirus structural protein. Cell 88: 223-233, 1997.

6. Fawell S, Seery J, Daikh Y, Moore C, Chen LL, Pepinsky B and Barsoum J: Tat-mediated delivery of heterologous proteins into cells. Proc Natl Acad Sci USA 91: 664-668, 1994.

7. Lewin M, Carlesso N, Tung CH, Tang XW, Cory D, Scadden DT and Weissleder R: Tat peptide-derivatized magnetic nanoparticles allow in vivo tracking and recovery of progenitor cells. Nat Biotechnol 18: 410-414, 2000.

8. Kumar P, Wu H, McBride JL, Jung KE, Kim MH, Davidson BL, Lee SK, Shankar P and Manjunath N: Transvascular delivery of small interfering RNA to the central nervous system. Nature 448: 39-43, 2007. 
9. Jafari S, Maleki Dizaj S and Adibkia K: Cell-penetrating peptides and their analogues as novel nanocarriers for drug delivery. Bioimpacts 5: 103-111, 2015.

10. Milletti F: Cell-penetrating peptides: Classes, origin, and current landscape. Drug Discov Today 17: 850-860, 2012.

11. Wender PA, Mitchell DJ, Pattabiraman K, Pelkey ET, Steinman L and Rothbard JB: The design, synthesis, and evaluation of molecules that enable or enhance cellular uptake: Peptoid molecular transporters. Proc Natl Acad Sci USA 97: 13003-13008, 2000.

12. Mai JC, Shen H, Watkins SC, Cheng T and Robbins PD: Efficiency of protein transduction is cell type-dependent and is enhanced by dextran sulfate. J Biol Chem 277: 30208-30218, 2002.

13. Tunnemann G, Ter-Avetisyan G, Martin RM, Stockl M, Herrmann A and Cardoso MC: Live-cell analysis of cell penetration ability and toxicity of oligo-arginines. J Pept Sci 14 469-476, 2008

14. Zahid M and Robbins PD: Cell-type specific penetrating peptides: Therapeutic promises and challenges. Molecules 20: 13055-13070, 2015.

15. Ragin AD, Morgan RA and Chmielewski J: Cellular import mediated by nuclear localization signal Peptide sequences. Chem Biol 9: 943-948, 2002.

16. Oehlke J, Scheller A, Wiesner B, Krause E, Beyermann M, Klauschenz E, Melzig M and Bienert M: Cellular uptake of an alpha-helical amphipathic model peptide with the potential to deliver polar compounds into the cell interior non-endocytically. Biochim Biophys Acta 1414: 127-139, 1998.

17. Deshayes S, Plénat T, Aldrian-Herrada G, Divita G Le Grimellec C and Heitz F: Primary amphipathic cell-penetrating peptides: Structural requirements and interactions with model membranes. Biochemistry 43: 7698-7706, 2004.

18. Nan YH, Park IS, Hahm KS and Shin SY: Antimicrobial activity, bactericidal mechanism and LPS-neutralizing activity of the cell-penetrating peptide pVEC and its analogs. J Pept Sci 17 812-817, 2011

19. Johansson HJ, El-Andaloussi S, Holm T, Mäe M, Jänes J, Maimets $\mathrm{T}$ and Langel $\mathrm{U}$ : Characterization of a novel cytotoxic cell-penetrating peptide derived from p14ARF protein. Mol Ther 16: 115-123, 2008

20. Magzoub M, Sandgren S, Lundberg P, Oglecka K, Lilja J, Wittrup A, Göran Eriksson LE, Langel U, Belting $M$ and Gräslund A: N-terminal peptides from unprocessed prion proteins enter cells by macropinocytosis. Biochem Biophys Res Commun 348: 379-385, 2006.

21. Eguchi A and Dowdy SF: siRNA delivery using peptide transduction domains. Trends Pharmacol Sci 30: 341-345, 2009.

22. Oehlke J, Krause E, Wiesner B, Beyermann M and Bienert M: Extensive cellular uptake into endothelial cells of an amphipathic beta-sheet forming peptide. FEBS Lett 415: 196-199, 1997.

23. Pujals S and Giralt E: Proline-rich, amphipathic cell-penetrating peptides. Adv Drug Deliv Rev 60: 473-484, 2008

24. Pooga M, Hällbrink M, Zorko M and Langel U: Cell penetration by transportan. FASEB J 12: 67-77, 1998

25. Schafmeister CE, Po J and Verdine GL: An all-hydrocarbon cross-linking system for enhancing the helicity and metabolic stability of peptides. J Am Chem Soc 122: 5891-5892, 2000.

26. Ochocki JD, Mullen DG, Wattenberg EV and Distefano MD: Evaluation of a cell penetrating prenylated peptide lacking an intrinsic fluorophore via in situ click reaction. Bioorg Med Chem Lett 21: 4998-5001, 2011.

27. Covic L, Gresser AL, Talavera J, Swift S and Kuliopulos A Activation and inhibition of $\mathrm{G}$ protein-coupled receptors by cell-penetrating membrane-tethered peptides. Proc Natl Acad Sci USA 99: 643-648, 2002.

28. Gao S, Simon MJ, Hue CD, Morrison B III and Banta S: An unusual cell penetrating peptide identified using a plasmid display-based functional selection platform. ACS Chem Biol 6: 484-491, 2011

29. Gao C, Mao S, Ditzel HJ, Farnaes L, Wirsching P, Lerner RA and Janda KD: A cell-penetrating peptide from a novel pVII-pIX phage-displayed random peptide library. Bioorg Med Chem 10 4057-4065, 2002.

30. Nakayama F, Yasuda T, Umeda S, Asada M, Imamura T, Meineke V and Akashi M: Fibroblast growth factor-12 (FGF12) translocation into intestinal epithelial cells is dependent on a novel cell-penetrating peptide domain: Involvement of internalization in the in vivo role of exogenous FGF12. J Biol Chem 286: 25823-25834, 2011
31. Fonseca SB, Pereira MP and Kelley SO: Recent advances in the use of cell-penetrating peptides for medical and biological applications. Adv Drug Deliv Rev 61: 953-964, 2009.

32. Madani F, Lindberg S, Langel U, Futaki S and Graslund A: Mechanisms of cellular uptake of cell-penetrating peptides. J Biophys 2011: 414729, 2011.

33. Choi YS and David AE: Cell penetrating peptides and the mechanisms for intracellular entry. Curr Pharm Biotechnol 15: 192-199, 2014

34. Wu X and Gehring W: Cellular uptake of the Antennapedia homeodomain polypeptide by macropinocytosis. Biochem Biophys Res Commun 443: 1136-1140, 2014.

35. Polanco C, Samaniego JL, Castañón-González JA, Buhse T and Sordo ML: Characterization of a possible uptake mechanism of selective antibacterial peptides. Acta Biochim Pol 60: 629-633, 2013.

36. Vivès E, Brodin $\mathrm{P}$ and Lebleu B: A truncated HIV-1 Tat protein basic domain rapidly translocates through the plasma membrane and accumulates in the cell nucleus. J Biol Chem 272: 16010-16017, 1997.

37. Derossi D, Joliot AH, Chassaing G and Prochiantz A: The third helix of the Antennapedia homeodomain translocates through biological membranes. J Biol Chem 269: 10444-10450, 1994.

38. Veach RA, Liu D, Yao S, Chen Y, Liu XY, Downs S and Hawiger J: Receptor/transporter-independent targeting of functional peptides across the plasma membrane. J Biol Chem 279: $11425-11431,2004$.

39. Herce HD and Garcia AE: Molecular dynamics simulations suggest a mechanism for translocation of the HIV-1 TAT peptide across lipid membranes. Proc Natl Acad Sci USA 104 20805-20810, 2007.

40. Pouny Y, Rapaport D, Mor A, Nicolas P and Shai Y: Interaction of antimicrobial dermaseptin and its fluorescently labeled analogues with phospholipid membranes. Biochemistry 31: 12416-12423, 1992.

41. Lee MT, Hung WC, Chen FY and Huang HW: Many-body effect of antimicrobial peptides: On the correlation between lipid's spontaneous curvature and pore formation. Biophys J 89: 4006-4016, 2005.

42. Richard JP, Melikov K, Vives E, Ramos C, Verbeure B, Gait MJ, Chernomordik LV and Lebleu B: Cell-penetrating peptides. A reevaluation of the mechanism of cellular uptake. J Biol Chem 278: 585-590, 2003.

43. Vivès E, Schmidt J and Pèlegrin A: Cell-penetrating and cell-targeting peptides in drug delivery. Biochim Biophys Acta 1786: 126-138, 2008

44. Jones AT: Macropinocytosis: Searching for an endocytic identity and role in the uptake of cell penetrating peptides. J Cell Mol Med 11: 670-684, 2007.

45. Mayor S, Parton RG and Donaldson JG: Clathrin-independent pathways of endocytosis. Cold Spring Harb Perspect Biol 6 : 6, 2014

46. Derossi D, Calvet S, Trembleau A, Brunissen A, Chassaing G and Prochiantz A: Cell internalization of the third helix of the Antennapedia homeodomain is receptor-independent. J Biol Chem 271: 18188-18193, 1996.

47. Kawamoto S, Takasu M, Miyakawa T, Morikawa R, Oda T, Futaki S and Nagao H: Inverted micelle formation of cell-penetrating peptide studied by coarse-grained simulation: Importance of attractive force between cell-penetrating peptides and lipid head group. J Chem Phys 134: 095103, 2011.

48. Tünnemann G, Martin RM, Haupt S, Patsch C, Edenhofer F and Cardoso MC: Cargo-dependent mode of uptake and bioavailability of TAT-containing proteins and peptides in living cells. FASEB J 20: 1775-1784, 2006

49. Lundberg P, El-Andaloussi S, Sütlü T, Johansson H and Langel U: Delivery of short interfering RNA using endosomolytic cell-penetrating peptides. FASEB J 21: 2664-2671, 2007.

50. Jones AT and Sayers EJ: Cell entry of cell penetrating peptides: tales of tails wagging dogs. J Control Release 161: 582-591,2012.

51. Mueller J, Kretzschmar I, Volkmer R and Boisguerin P: Comparison of cellular uptake using 22 CPPs in 4 different cell lines. Bioconjug Chem 19: 2363-2374, 2008.

52. Pysz MA, Gambhir SS and Willmann JK: Molecular imaging: Current status and emerging strategies. Clin Radiol 65: 500-516, 2010.

53. Condeelis $\mathrm{J}$ and Weissleder R: In vivo imaging in cancer. Cold Spring Harb Perspect Biol 2: a003848, 2010.

54. Walling MA, Novak JA and Shepard JRE: Quantum dots for live cell and in vivo imaging. Int J Mol Sci 10: 441-491, 2009. 
55. Ruan G, Agrawal A, Marcus AI and Nie S: Imaging and tracking of tat peptide-conjugated quantum dots in living cells: New insights into nanoparticle uptake, intracellular transport, and vesicle shedding. J Am Chem Soc 129: 14759-14766, 2007.

56. Lei Y, Tang H, Yao L, Yu R, Feng M and Zou B: Applications of mesenchymal stem cells labeled with Tat peptide conjugated quantum dots to cell tracking in mouse body. Bioconjug Chem 19: 421-427, 2008.

57. Prantner AM, Sharma V, Garbow JR and Piwnica-Worms D Synthesis and characterization of a Gd-DOTA-D-permeation peptide for magnetic resonance relaxation enhancement of intracellular targets. Mol Imaging 2: 333-341, 2003.

58. Polyakov V, Sharma V, Dahlheimer JL, Pica CM, Luker GD and Piwnica-Worms D: Novel Tat-peptide chelates for direct transduction of technetium- $99 \mathrm{~m}$ and rhenium into human cells for imaging and radiotherapy. Bioconjug Chem 11: 762-771, 2000.

59. Jiménez-Mancilla N, Ferro-Flores G, Santos-Cuevas C Ocampo-García B, Luna-Gutiérrez M, Azorín-Vega E, Isaac-Olivé K, Camacho-López $\mathrm{M}$ and Torres-García E: Multifunctional targeted therapy system based on (99m) Tc/(177) Lu-labeled gold nanoparticles-Tat(49-57)-Lys(3) -bombesin internalized in nuclei of prostate cancer cells. J Labelled Comp Radiopharm 56: 663-671, 2013.

60. Santos-Cuevas CL, Ferro-Flores G, Rojas-Calderón EL, García-Becerra R, Ordaz-Rosado D, Arteaga de Murphy C and Pedraza-López M: 99mTc-N2S2-Tat (49-57)-bombesin internalized in nuclei of prostate and breast cancer cells: Kinetics dosimetry and effect on cellular proliferation. Nucl $\mathrm{Mec}$ Commun 32: 303-313, 2011.

61. Weinstain R, Savariar EN, Felsen CN and Tsien RY: In vivo targeting of hydrogen peroxide by activatable cell-penetrating peptides. J Am Chem Soc 136: 874-877, 2014.

62. Good L, Awasthi SK, Dryselius R, Larsson O and Nielsen PE: Bactericidal antisense effects of peptide-PNA conjugates. Nat Biotechnol 19: 360-364, 2001.

63. Deshayes S, Konate K, Aldrian G, Crombez L, Heitz F and Divita G: Structural polymorphism of non-covalent peptide-based delivery systems: Highway to cellular uptake. Biochim Biophys Acta 1798: 2304-2314, 2010.

64. Tan XX, Actor JK and Chen Y: Peptide nucleic acid antisense oligomer as a therapeutic strategy against bacterial infection: Proof of principle using mouse intraperitoneal infection. Antimicrob Agents Chemother 49: 3203-3207, 2005.

65. Tilley LD, Mellbye BL, Puckett SE, Iversen PL and Geller BL: Antisense peptide-phosphorodiamidate morpholino oligomer conjugate: Dose-response in mice infected with Escherichia coli. J Antimicrob Chemother 59: 66-73, 2007

66. Makarov SS: NF-kappa B in rheumatoid arthritis: A pivotal regulator of inflammation, hyperplasia, and tissue destruction. Arthritis Res 3: 200-206, 2001.

67. Brown JD, Lin CY, Duan Q, Griffin G, Federation AJ, Paranal RM, Bair S, Newton G, Lichtman AH, Kung AL, et al $\mathrm{NF}-\kappa \mathrm{B}$ directs dynamic super enhancer formation in inflammation and atherogenesis. Mol Cell 56: 219-231, 2014

68. Hunot S, Brugg B, Ricard D, Michel PP, Muriel MP, Ruberg M, Faucheux BA, Agid Y and Hirsch EC: Nuclear translocation of NF-kappaB is increased in dopaminergic neurons of patients with parkinson disease. Proc Natl Acad Sci USA 94: 7531-7536, 1997.

69. Karin M and Greten FR: NF-kappaB: Linking inflammation and immunity to cancer development and progression. Nat Rey Immunol 5: 749-759, 2005.

70. May MJ, D'Acquisto F, Madge LA, Glöckner J, Pober JS and Ghosh S: Selective inhibition of NF-kappaB activation by a peptide that blocks the interaction of NEMO with the IkappaB kinase complex. Science 289: 1550-1554, 2000.

71. Davé SH, Tilstra JS, Matsuoka K, Li F, Karrasch T, Uno JK, Sepulveda AR, Jobin C, Baldwin AS, Robbins PD and Plevy SE: Amelioration of chronic murine colitis by peptide-mediated transduction of the IkappaB kinase inhibitor NEMO binding domain peptide. J Immunol 179: 7852-7859, 2007.

72. Peterson JM, Kline W, Canan BD, Ricca DJ, Kaspar B, Delfín DA DiRienzo K, Clemens PR, Robbins PD, Baldwin AS, et al: Peptide-based inhibition of NF- $\kappa \mathrm{B}$ rescues diaphragm muscle contractile dysfunction in a murine model of Duchenne muscular dystrophy. Mol Med 17: 508-515, 2011.

73. Hegedüs R, Manea M, Orbán E,Szabó I,Kiss E, Sipos E, Halmos G and Mező G: Enhanced cellular uptake and in vitro antitumor activity of short-chain fatty acid acylated daunorubicin-GnRH-III bioconjugates. Eur J Med Chem 56: 155-165, 2012.
74. Pan L, Liu J, He Q, Wang L and Shi J: Overcoming multidrug resistance of cancer cells by direct intranuclear drug delivery using TAT-conjugated mesoporous silica nanoparticles. Biomaterials 34: 2719-2730, 2013.

75. Kondo E, Saito K, Tashiro Y, Kamide K, Uno S, Furuya T, Mashita M, Nakajima K, Tsumuraya T, Kobayashi N, et al: Tumour lineage-homing cell-penetrating peptides as anticancer molecular delivery systems. Nat Commun 3: 951, 2012.

76. Koshkaryev A, Piroyan A and Torchilin VP: Bleomycin in octaarginine-modified fusogenic liposomes results in improved tumor growth inhibition. Cancer Lett 334: 293-301, 2013.

77. Walker L, Perkins E, Kratz F and Raucher D: Cell penetrating peptides fused to a thermally targeted biopolymer drug carrier improve the delivery and antitumor efficacy of an acid-sensitive doxorubicin derivative. Int J Pharm 436: 825-832, 2012

78. Aroui S, Mili D, Brahim S, De Waard M and Kenani A Doxorubicin coupled to penetratin promotes apoptosis in $\mathrm{CHO}$ cells by a mechanism involving c-Jun NH2-terminal kinase. Biochem Biophys Res Commun 396: 908-914, 2010.

79. Dubikovskaya EA, Thorne SH, Pillow TH, Contag $\mathrm{CH}$ and Wender PA: Overcoming multidrug resistance of small-molecule therapeutics through conjugation with releasable octaarginine transporters. Proc Natl Acad Sci USA 105: 12128-12133, 2008.

80. Lindgren M, Rosenthal-Aizman K, Saar K, Eiríksdóttir E, Jiang Y, Sassian M, Ostlund P, Hällbrink M and Langel U: Overcoming methotrexate resistance in breast cancer tumour cells by the use of a new cell-penetrating peptide. Biochem Pharmacol 71: 416-425, 2006.

81. Kanasty R, Dorkin JR, Vegas A and Anderson D: Delivery materials for siRNA therapeutics. Nat Mater 12: 967-977, 2013.

82. Muratovska A and Eccles MR: Conjugate for efficient delivery of short interfering RNA (siRNA) into mammalian cells. FEBS Lett 558: 63-68, 2004.

83. Favaro MT, de Toledo MA, Alves RF, Santos CA, Beloti LL, Janissen R, de la Torre LG, Souza AP and Azzoni AR: Development of a non-viral gene delivery vector based on the dynein light chain Rp3 and the TAT peptide. J Biotechnol 173: 10-18, 2014.

84. Wang HY, Chen JX, Sun YX, Deng JZ, Li C, Zhang XZ and Zhuo RX: Construction of cell penetrating peptide vectors with $\mathrm{N}$-terminal stearylated nuclear localization signal for targeted delivery of DNA into the cell nuclei. J Control Release 155: 26-33, 2011

85. Schott JW, Galla M, Godinho T, Baum C and Schambach A: Viral and non-viral approaches for transient delivery of mRNA and proteins. Curr Gene Ther 11: 382-398, 2011.

86. Eto Y, Yoshioka Y, Asavatanabodee R, Kida S, Maeda M, Mukai Y, Mizuguchi H, Kawasaki K, Okada N and Nakagawa S: Transduction of adenovirus vectors modified with cell-penetrating peptides. Peptides 30: 1548-1552, 2009

87. Gratton JP, Yu J, Griffith JW, Babbitt RW, Scotland RS, Hickey R, Giordano FJ and Sessa WC: Cell-permeable peptides improve cellular uptake and therapeutic gene delivery of replication-deficient viruses in cells and in vivo. Nat Med 9: 357-362, 2003.

88. Takahashi K, Tanabe K, Ohnuki M, Narita M, Ichisaka T, Tomoda $\mathrm{K}$ and Yamanaka S: Induction of pluripotent stem cells from adult human fibroblasts by defined factors. Cell 131: 861-872, 2007

89. Ebrahimi B: Reprogramming barriers and enhancers: Strategies to enhance the efficiency and kinetics of induced pluripotency. Cell Regen (Lond) 4: 10, 2015.

90. Gotoh S, Ito I, Nagasaki T, Yamamoto Y, Konishi S, Korogi Y, Matsumoto H, Muro S, Hirai T, Funato M, et al: Generation of alveolar epithelial spheroids via isolated progenitor cells from human pluripotent stem cells. Stem Cell Rep 3: 394-403, 2014.

91. Kamao H, Mandai M, Okamoto S, Sakai N, Suga A, Sugita S, Kiryu J and Takahashi M: Characterization of human induced pluripotent stem cell-derived retinal pigment epithelium cell sheets aiming for clinical application. Stem Cell Rep 2: 205-218, 2014.

92. Waehler R, Russell SJ and Curiel DT: Engineering targeted viral vectors for gene therapy. Nat Rev Genet 8: 573-587, 2007.

93. Woltjen K, Michael IP, Mohseni P, Desai R, Mileikovsky M, Hämäläinen R, Cowling R, Wang W, Liu P, Gertsenstein M, et al: piggyBac transposition reprograms fibroblasts to induced pluripotent stem cells. Nature 458: 766-770, 2009. 